\title{
Primary-care providers' perceived barriers to integration of genetics services: a systematic review of the literature
}

\author{
Natalie A. Mikat-Stevens, MPH${ }^{1}$, Ingrid A. Larson, RN, CPNP² and Beth A. Tarini, MD, MS ${ }^{3}$
}

Purpose: We aimed to systematically review the literature to identify primary-care providers' perceived barriers against provision of genetics services.

Methods: We systematically searched PubMed and ERIC using key and Boolean term combinations for articles published from 2001 to 2012 that met inclusion/exclusion criteria. Specific barriers were identified and aggregated into categories based on topic similarity. These categories were then grouped into themes.

Results: Of the 4,174 citations identified by the search, 38 publications met inclusion criteria. There were 311 unique barriers that were classified into 38 categories across 4 themes: knowledge and skills; ethical, legal, and social implications; health-care systems; and scientific evidence. Barriers most frequently mentioned by primary-care providers included a lack of knowledge about genetics and genetic risk assessment, concern for patient anxiety, a lack of access to genetics, and a lack of time.

Conclusion: Although studies reported that primary-care providers perceive genetics as being important, barriers to the integration of genetics medicine into routine patient care were identified. The promotion of practical guidelines, point-of-care risk assessment tools, tailored educational tools, and other systems-level strategies will assist primary-care providers in providing genetics services for their patients.

Genet Med advance online publication 11 September 2014

Key Words: barriers; genetics; genetics services; primary care; systematic review

\section{INTRODUCTION}

Although historically concerned with the identification and diagnosis of rare diseases, the field of medical genetics has expanded its scope in the past decade to include the identification of patients at risk for genetically based conditions and the provision of preventive health interventions. Because the practice of preventive medicine for common conditions is the mainstay of primary care, primary-care providers (PCPs) are critical to the success of this expansion of medical genetics. PCPs are responsible for gathering family history $(\mathrm{FH})$, performing risk assessments, ordering tests, and specialist referrals. Yet barriers may interfere with PCPs' willingness to embrace and perform these tasks, which are vital to the integration of genetics into primary-care practice. In fact, shortly after the completion of the Human Genome Project (HGP), ${ }^{1}$ Suther and Goodson ${ }^{2}$ conducted a systematic review of the literature and identified numerous barriers to the successful integration of genetics into primary-care medicine practice, including inadequate PCP knowledge of basic genetics, lack of detailed or updated FHs, lack of PCP confidence, and lack of referral guidelines.

More than a decade after the completion of the HGP, our understanding of the relationship between genetics and common disease, as well as our technological capabilities to identify genetic abnormalities, has advanced significantly. Yet our understanding of the barriers to the integration of genetics into primary-care medicine has not been revisited. Therefore, we sought to reassess our understanding of the barriers to the integration of genetics services into primary care by conducting a systematic review of the medical literature.

\section{MATERIALS AND METHODS \\ Study selection criteria}

We conducted a systematic review of research studies in which new data were gathered and that examined PCP-identified barriers to the integration of genetics services into primary care. We chose a priori to include studies that addressed barriers related to the following areas of genetics services: genetic testing and screening, pharmacogenomics, and the evaluation, diagnosis, and management of genetic conditions.

For this review, we used the definition of primary care provided by the Institute of Medicine Committee on the Future of Primary Care, which defines primary care as "the provision of integrated, accessible health care services by clinicians who are accountable for addressing a large majority of personal health care needs, developing a sustained partnership with patients, and practicing in the context of family and community."3 Therefore, we included the following types of nonstudent/nonresident clinicians in our definition of PCPs: pediatricians, family physicians or general practitioners, obstetricians and gynecologists, and primary-care advanced-practice registered nurses and

\footnotetext{
${ }^{1}$ American Academy of Pediatrics, Elk Grove Village, Illinois, USA; ${ }^{2}$ Division of General Pediatrics, The Children's Mercy Hospitals and Clinics, Kansas City, Missouri, USA; ${ }^{3}$ Child Health Evaluation and Research Unit, Department of Pediatrics, University of Michigan, Ann Arbor, Michigan, USA. Correspondence: Natalie A. Mikat-Stevens (n.mikatstevens@gmail.com)
} 
physician assistants. Finally, we selected published research studies in which the subjects of the study were PCPs and barriers were explicitly identified by the PCPs. We did so to avoid identifying barriers based on assumptions made by non-PCPs.

\section{Literature search}

We queried PubMed and ERIC using key terms to identify articles published from 2001 through 2012. We chose 2001 as the beginning of our time period because this was the last publication year for articles included in the review by Suther and Goodson. ${ }^{2}$ We searched using key terms "genetics," "genetic testing," or "genetic screening" combined (through the Boolean term "and") with "primary care providers," "primary care physicians," "primary care," "physicians," "family practice," "general practitioners," "pediatricians," "pediatric providers," or "pediatric practitioners." This search generated 4,174 citations, which were reviewed independently by three reviewers. Articles were excluded if review of title indicated that they did not meet selection criteria. Review of remaining abstracts $(n=350)$ identified 98 articles that required a full review to determine whether they met inclusion/exclusion criteria. Of these, 60 were excluded based on the above exclusion criteria, yielding a final sample of 38 studies for analysis (Figure 1). At every step in the review process, any disagreement regarding exclusion was discussed among the three reviewers.

\section{Data abstraction and analysis}

The first step in analysis of the studies was to extract data on PCPs' self-reported barriers to delivering genetics services. Each study was reviewed by two authors (one of whom was the lead author), and specific barriers within each study were identified. Of note, an individual study could contain data on more than one barrier. We recorded the number of times a specific barrier appeared across studies. Next, the barriers from all studies were aggregated into categories based on similarity of topic. For example, a lack of genetic knowledge was one barrier category. Within this category we grouped general genetic knowledge barriers as well as more specific knowledge

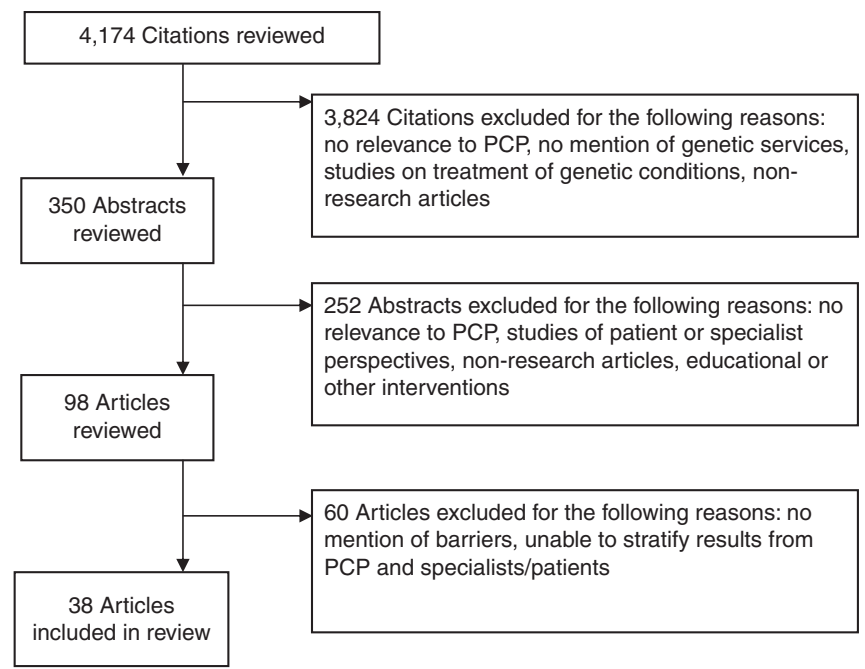

Figure 1 Study selection process. PCP, primary-care provider. barriers. Finally, we organized the barrier categories into the following themes: (i) knowledge/skills (i.e., described selfreported deficiencies in understanding concepts or performing tasks); (ii) ethical, legal, and social implications (ELSI) (also included barriers that addressed psychosocial aspects of genetics); (iii) health-care systems (i.e., related to practical challenges, procedures, and policies); and (iv) scientific evidence (i.e., professional guidelines and strength of scientific evidence related to genetic evaluation and testing). The barriers were organized through an iterative process, and we did not use a previously published framework. Rather, we considered the context in which the barrier could be targeted (i.e., a competency deficit versus a clinic workflow issue) to organize the results. Additional data extracted from the studies included sample size, country of study, study methodology, subject demographics and response rate, study objective, and additional conclusions, such as overall attitudes and perceptions regarding the integration of genetics into primary-care practice (Supplementary Table S1 online).

We also assessed the quality of the studies. We were unaware of any validated tools that assess the quality of cross-sectional surveys or qualitative studies for systematic reviews. Therefore, we created our own metric for assessing the quality of a quantitative survey, which was the study design for all but one of the quantitative studies (Hindorff et al. ${ }^{4}$ was a case-control study). We used a checklist tool used in a previous systematic review for qualitative studies. ${ }^{5}$

In survey research, minimizing bias is critical to the collection of valid data. Therefore we constructed a simple assessment tool based on this concept. The most significant sources of bias during data collection in survey research include sample bias due to the use of a nonrepresentative sample (e.g., a nonrandom subsample of the population or a convenience sample) and attrition bias due to low response rates (we set a 50\% cutoff). Because we have no evidence as to the relative contribution to or weight of each of these elements in the measure of bias, we assigned them equal weight. We calculated a bias risk score that gives 1 point for each source of bias (highest total score $=2$ ). We feel that this addresses potential limitations regarding assessment of the relationship between the sample size of the study and the validity of the findings. Generalization of the findings depends more on the representativeness of a sample than its absolute size.

For qualitative studies, we used the nonvalidated, 28 -item checklist tool used by Tong et al. ${ }^{5}$ in a recent systematic review of qualitative studies. Similarly, because we have no evidence as to the relative contribution to or weight of each of the individual elements in this checklist, we assigned them equal weight (highest total score $=28$ ).

\section{RESULTS}

A total of 38 published research studies met the criteria for inclusion in this review (Figure 1). Of these, 24 studies used quantitative methods and 13 used qualitative methods (Table 1). We identified 311 barriers (nonunique) across all 38 studies, which were aggregated into 38 unique categories within 
4 thematic areas, which are described below (Supplementary Table $\mathbf{S 2}$ online).

The majority of articles $(n=19)$ included in this review evaluated the perceptions of mixed cohorts of PCPs, whereas 17 studies included only general practitioners or family physicians. One study assessed only pediatricians and another included only obstetrics/gynecology providers. Because of the inability to identify PCP types in the majority of studies, we did not attempt to stratify our results by provider type. Seventeen studies were from the United States, 6 were from the United Kingdom, 4 were from Canada, and 11 were from other countries. It was difficult to compare studies across countries because of the wide array of countries represented and the small number of studies (Supplementary Table S1 online).

\section{Table 1 Study demographics}

\begin{tabular}{|c|c|}
\hline Category & Studies, \% (n) \\
\hline \multicolumn{2}{|l|}{ Study type } \\
\hline Quantitative & $63.2 \%(24)$ \\
\hline Qualitative & $34.2 \%(13)$ \\
\hline Other & $2.6 \%(1)$ \\
\hline Total & $100 \%(38)$ \\
\hline \multicolumn{2}{|l|}{ Study population } \\
\hline Mixed cohort & $50 \%(19)$ \\
\hline General practitioners/family medicine & $44.7 \%(17)$ \\
\hline Pediatricians & $2.6 \%(1)$ \\
\hline Obstetricians/gynecologists & $2.6 \%(1)$ \\
\hline Total & $100 \%(38)$ \\
\hline \multicolumn{2}{|l|}{ Nation } \\
\hline United States & $44.7 \%(17)$ \\
\hline Other countries & $55.3 \%(21)$ \\
\hline United Kingdom & $15.8 \%(6)$ \\
\hline Canada & $10.5 \%(4)$ \\
\hline Australia & $10.5 \%(4)$ \\
\hline Netherlands & $7.9 \%(3)$ \\
\hline New Zealand & $2.6 \%(1)$ \\
\hline Germany & $2.6 \%(1)$ \\
\hline Switzerland & $2.6 \%(1)$ \\
\hline Total & $100 \%(38)$ \\
\hline \multicolumn{2}{|l|}{ Study quality } \\
\hline \multicolumn{2}{|l|}{ Qualitative } \\
\hline Studies $(n)$ & 13 \\
\hline Quality score (highest = 28) & $\begin{array}{l}\text { Average }=13 \\
\text { (range: } 9-23 \text { ) }\end{array}$ \\
\hline \multicolumn{2}{|l|}{ Quantitative } \\
\hline Studies $(n)$ & 24 \\
\hline Average PCPs queried $(n)$ & $\begin{array}{l}\text { Average }=371 \\
\text { (range: } 34-1,251)\end{array}$ \\
\hline Sample randomness ( $0=$ no; 1 = yes) & $\begin{array}{l}\text { Average }=0.42 \\
\quad \text { (range: } 0-1)\end{array}$ \\
\hline Response rate $(>50 \%, 0=$ no; $1=$ yes $)$ & $\begin{array}{l}\text { Average }=0.46 \\
\quad \text { (range: } 0-1)\end{array}$ \\
\hline $\begin{array}{l}\text { Total bias score (sum of sample randomness and } \\
\text { response rate; highest }=2 \text { ) }\end{array}$ & $\begin{array}{l}\text { Average }=0.88 \\
\text { (range: } 0-2 \text { ) }\end{array}$ \\
\hline
\end{tabular}

We found a range of biases across the quantitative studies. Using our bias score, 9 studies had a score of 0,9 had a score of 1 , and 6 had a score of 2 (the highest). The qualitative studies varied in quality, with a range in quality score between 9 and 23 of 28 possible and an average score of 13 . All 13 qualitative studies received points for describing methods of sampling and sample size, providing a description of the sample, using an interview guide, deriving themes in data analysis, and providing respondent quotations.

\section{Knowledge and skills}

In total, 22 different knowledge and skills barriers were cited 84 times in the included studies; these barriers related to deficits in PCPs' knowledge and skills, confidence, comfort, and ability to perform specific genetic tasks (Supplementary Figure S1 online). The most commonly cited barrier category within this theme was a general lack of genetic knowledge $(n=24$ cited in 20/38 studies); this included specific barriers around PCPs' self-reported lack of confidence in their own knowledge about genetics in general $(n=7)^{6-12}$ and about clinical genetics, ${ }^{13}$ an interest in gaining insight regarding the genetic background of a disease,${ }^{14}$ and a lack of confidence in their ability to perform core competencies such as taking an $\mathrm{FH},{ }^{15}$ including a lack of knowledge about what $\mathrm{FH}$ information to collect. ${ }^{16}$

Among the several skill-related barriers identified, the most commonly cited ( $n=16$ citations in $16 / 38$ studies) was a lack of confidence their ability to counsel patients about genetic risk and to manage them. Specifically, providers expressed concerns about feeling unqualified to provide genetic counseling to patients and making the correct management decisions. Freedman and colleagues ${ }^{17}$ surveyed 1,763 US physicians and found that only $28.8 \%$ of PCPs felt qualified to provide genetic counseling to their patients. Several studies mentioned insufficient knowledge to counsel patients ${ }^{18}$ or a lack in confidence or comfort in doing so. ${ }^{9,13,19,20}$ In regard to FH, PCPs reported a lack of awareness of guidelines or recommendations for interpreting $\mathrm{FH}$; some knew guidelines existed but did not know the content ${ }^{21}$ or what to do with the results. ${ }^{14}$ Iredale et al..$^{22}$ reported that PCPs were unsure how to address consanguinity with their patients.

Fourteen of the 38 studies described the barriers of a lack of confidence or ability to order a genetic test and the interpretation of genetic test results (Supplementary Table S2 online). Specifically, PCPs reported difficulty explaining the limitations of screening tests to patients, and issues with false-negative and false-positive test results, as well as with general interpretation of genetic tests results, which they often found ambiguous. For example, Bonter et al. ${ }^{11}$ surveyed 341 Canadian physicians; less than $10 \%$ of family physicians surveyed reported that they were sufficiently informed about genetic testing, and only $15 \%$ of respondents reported feeling able to interpret genetic test results.

Ten studies identified barriers related to providers' ability to conduct genetic risk assessment. Specifically, PCPs cited a lack of knowledge and skills in assessing patient risk ${ }^{21}$ and testing 
for cancer susceptibility, ${ }^{15,17}$ as well as citing a lack of overall confidence in assessing patient risk. ${ }^{7,23}$ In their assessment of 860 US PCPs, Vig et al. ${ }^{24}$ found that $38.3 \%$ were uncomfortable with making screening and prevention recommendations and were uncertain about which patients are medically appropriate to refer.

PCPs reported that it was hard to keep up to date with evidence, specifically updated and revised professional guidelines ( $n=9$, citations of barrier in 9/38 studies). ${ }^{16,21,25-30}$ A lack of access to current information about genetics and being unaware of existing educational resources were also identified as barriers. ${ }^{10,12,25,31}$ When general practitioners in Australia were asked to nominate resources that would be valuable to them, they requested point-of-care resources to guide risk assessment.

Finally, barriers regarding the knowledge/skills for seeking referrals for medical genetics were cited on seven occasions. These encompassed a lack of understanding and confidence in how and when to make a referral to a genetic professional. ${ }^{14,24}$

\section{Ethical, legal, and social implications}

The majority of the studies reported at least one barrier related to the ELSI of genetics for both providers and patients. These were classified into 10 categories (Supplementary Figure S2 online). The most frequently cited ELSI barrier ( $n=18$ citations in 16/38 studies) was the potential for patient anxiety and psychological distress around genetic risk.,11,32 PCPs mentioned the potential for a patient to react with anxiety to genetic test results ${ }^{33}$ and that these results would put a burden on people who do not want to know about it, make carriers feel less healthy, ${ }^{34}$ and potentially make patients feel "inadequate."35 PCPs also mentioned that genetic testing may have unanticipated findings that are secondary to the intent of ordering testing and that may cause distress among adults and minors regarding adult-onset disorders. ${ }^{35,36}$

The second most common ELSI barrier $(n=15$ citations in $15 / 38$ studies) was the fear of social or insurance discrimination for their patients as a result of their genetic information. ${ }^{37}$ Freedman et al. ${ }^{17}$ found that more than $80 \%$ of 1,251 US PCPs surveyed thought that patients with positive genetic testing results were at risk for insurance discrimination. Another survey identified $70 \%$ of PCPs with this concern. ${ }^{38}$ In addition, Lowstuter et al..$^{38}$ found that $75 \%$ of a sample of 1,222 California physicians thought that patients will decline testing for fear of health insurance discrimination. Of note, both of these studies were conducted before the enactment of the Genetic Information Nondiscrimination Act in 2008.

The concern over lack of confidentiality of genetic information, specifically the risk of harm resulting from a breach of privacy and disclosure of information, was cited as a barrier on 10 occasions. Examples of disclosure concerns included revelations of nonpaternity, as well as the implications of uncovering genetic risk for family members of the primary patient. In a national survey, $53 \%$ of PCPs felt it difficult to ensure that patients' test results will remain confidential. ${ }^{17}$ In another study, $61 \%$ of Swiss physicians feared that confidentiality could be breached because the breast cancer test result had implications for other family members. ${ }^{39}$ Several issues related to prenatal ethics arose, including the perception that prenatal genetic testing dampens the natural excitement of pregnancy or could medicalize pregnancy and a fear that prenatal and preconception genetic testing would motivate individuals to want to create a "perfect child," which might create additional disparities in society regarding individuals with genetic conditions or disabilities. ${ }^{26,39}$ The concept that genetics has the ability to cause "more harm than good" was also expressed as a concern. ${ }^{25,26,32,37,39}$

\section{Systems}

A total of 40 individual barriers related to health-care systems (Supplementary Figure S3 online). The largest category of systems barriers was lack of access to genetics services ( $n$ $=23$ citations in 17/38 studies). This encompassed specific barriers related to lack of access to genetics services in general $^{9,15,19,33}$ and a specific lack of access to genetic counselors or geneticists. ${ }^{2,15,22,24,25,37,40,41}$ PCPs reported an inability to obtain a consultation with clinicians in four studies, noting that the location of the nearest genetics center was too inconvenient for patients to be able to access. ${ }^{22,24,29,40}$ Chen et al. ${ }^{29}$ found that $24 \%$ of Alabama pediatricians surveyed were unable to obtain genetics consultations for their patients, $67 \%$ said it was difficult or not possible to obtain a face-to-face genetics evaluation, and $58 \%$ reported it was difficult or impossible to obtain a remote genetics evaluation. Iredale et al..$^{22}$ found that rural location played a major role in access issues because of isolation, lack of social networks, poor transport, decreased accessibility, and lack of referral patterns to secondary and tertiary facilities. In several studies, PCPs reported that genetic testing was not readily available to them. ${ }^{4,11,17,33,40}$

The second most frequently cited systems barriers related to time ( $n=21$ cited in 18/38 studies). This included time needed to collect detailed FHs as part of the primary-care visit ${ }^{22,27}$ and having insufficient time to explain the results of genetic tests to patients. ${ }^{11,21,29}$ In the case of genetic medicine in prenatal care, the time to obtain results was reported as being too long to inform any treatment decisions. ${ }^{11,15}$

PCPs also reported being unclear about their role in providing genetics services ( $n=15$ cited in $15 / 38$ studies). In some instances, PCPs felt that it was not their role to deliver genetics services ${ }^{8,36,39}$ or they simply were unclear about their role. $912-14,32,37$ Additional studies described PCPs' perceptions that "genetics is for specialists" $19,27,29,40$ and that the management of genetic conditions requires complex high-level knowledge available only from a specialist. Furthermore, the perception that genetics was less prevalent or significant than other issues was identified as a barrier in eight studies. This included the notion that genetics was not perceived to have an impact on primary-care practice. ${ }^{7,12,23,25,27,33,42}$

Cost to both patients and providers was expressed as a barrier to integration of genetics services into primary care. This included a barrier in regard to the lack of insurance coverage for 
genetic tests ( $n=6$ citations), as well as the cost to the patient ( $n=10$ citations). Costs for PCPs also were cited as a barrier, particularly regarding unreimbursed time spent counseling and ordering genetic tests. ${ }^{11,12,18,42}$

Several practical barriers regarding the integration of genetics into the system of primary-care practice were mentioned. Among the most common was the notion that it is difficult to incorporate additional genetics tasks into practice/clinic flow ( $n=8$ cited in $5 / 38$ studies). ${ }^{4,9,10,28,30}$ In addition, PCPs reported having insufficient tools to assess cancer risk and that it was difficult to enter FH information into the electronic health record. ${ }^{14,31}$ PCPs reported that their patients' accuracy when providing FH information was a barrier, ${ }^{16,21,27,28}$ as were language and culture barriers when discussing $\mathrm{FH}$ and genetics with patients. . $1421,22,27^{2}$

\section{Evidence}

A total of nine barriers related to current scientific evidence behind use of genetics services were identified in the studies (Supplementary Figure S4 online); the most commonly cited barrier was a perceived lack of therapeutic interventions available after the identification of increased risk ( $n=11$ cited in $11 / 38$ studies $)^{24,27,28,36,39}$ and the notion that patient management would not change as a result of genetic assessment. ${ }^{4,7,11,23,25,27}$ The second most frequently cited evidence barrier reported was the lack of guidelines and insufficient evidence to support risk assessment ( $n=10$ cited in 10/38 studies).

A lack of guidelines for when to order a genetic test was mentioned as a barrier $(n=6)$. Furthermore, PCPs reported that limitations of current genetic screening tests deterred them from utilizing them in practice $(n=10$ cited in $7 / 38$ studies). Specific limitations of genetic tests were inaccurate or unambiguous results, $, 17,29$ a high rate of false positives (in cancer risk testing), ${ }^{17,33}$ and concern over the validity of genetic testing. ${ }^{9,33}$ In a study of more than 1,200 US physicians, $45 \%$ believed patients' risk of cancer is unclear after genetic testing. ${ }^{17}$

\section{Most significant barriers}

Among quantitative studies, sample size is likely to contribute to a more representative assessment of the study population. Because the barriers identified in each study were given equal weight, we also assessed the barriers from the largest studies (those that had a sample size of $\geq 400 ; n=7$ ) in an attempt to ascertain the relative priority of the barriers identified. We found that the barriers in the largest studies reflect the distribution of barriers across the four categories. Of the seven largest studies, four studies were conducted in the United States and discussed a lack of genetic knowledge and challenges with access to genetics services; three studies discussed a perceived lack of therapeutic interventions and fear of insurance discrimination; two studies mentioned lack of clear or accessible guidelines to support risk assessment, lack of confidence in genetic referrals, lack of confidence and ability to order genetic tests, and a lack of time.
Thirteen other barriers were mentioned once across the largest studies.

\section{DISCUSSION}

This systematic review found that numerous challenges to the integration of genetics services into the routine provision of primary care remain a decade after completion of the HGP. Although four major barrier themes (knowledge/skills, systems, ELSI, and evidence) were identified, barriers related to insufficient knowledge and skills were the most frequently cited across the literature. A similar systematic review by Suther and Goodson ${ }^{2}$ conducted 12 years ago reached the same conclusion.

Why does knowledge still loom larger as a barrier? What does it mean for the successful integration of genetics into primary care? One reason may be that before PCPs even set foot in the clinic, they are already behind. Time has not stood still for the field of genetics since the completion of the HGP. On the contrary, advances in genetic technology and the discovery of new genetic mechanisms seem to occur almost daily. Meanwhile, PCPs' genetics training is likely decades old and rusty from lack of use. Until only recently, the field of genetics has focused on rare diseases that are not frequently seen in a primary-care clinic. Yet the real challenge for providers is when and how to apply this information in their practice. A "trainthe-trainer" model might be a helpful practical approach to addressing knowledge and competency barriers to the integration of genetics into primary care.

Although a lack of professional guidelines was cited as a barrier, we were unable to determine from the data whether this was because of an actual lack or the lack of awareness of the same. For example, Vig et al. ${ }^{24}$ found that $16.7 \%$ of physicians use professional guidelines to guide referral for cancer genetics evaluation. It is possible that dissemination and uptake of guidelines is incomplete given their recent development at the time of data collection. In the past 10 years, professional societies such as the American Academy of Pediatrics, ${ }^{43,44}$ the American College of Obstetricians and Gynecologists, ${ }^{45}$ the American Society of Clinical Oncology, ${ }^{46}$ and the American College of Medical Genetics and Genomics ${ }^{47,48}$ have published numerous guidelines on topics that could potentially be useful for PCPs.

Systems-level barriers collectively were noted as the most significant impediment to PCPs integrating genetics into their practice, particularly time constraints and lack of access to services. A solution might be the use of quality improvement strategies and process mapping to examine patient and clinician workflow in order to facilitate the integration of $\mathrm{FH}$ collection and genetic assessment. Barriers related to health information technology were largely not addressed in the studies reviewed, likely because the use of electronic health records in the primary-care setting over the past decade has increased significantly. ${ }^{49,50}$ Recent interventions aimed at improving the integration of genetics medicine into primary care have demonstrated significant barriers toward collecting and updating 
FH information in electronic health records. Patient-entered FH data, including the use of electronic risk assessment models, has been demonstrated to reduce the time required by healthcare professionals to collect information and has not resulted in poorer quality of data. ${ }^{51,52}$ Point-of-care FH tools provide actionable clinical decision support for PCPs and have been developed for prenatal care, ${ }^{53,54}$ family medicine, ${ }^{55}$ and pediatrics. The exponential increase of genetic and genomic information is quickly exceeding the ability of humans to remember and process. PCPs in particular should be equipped to use existing resources, as opposed to learning endless facts. ${ }^{63}$ This model has been effective for pharmacogenomics. ${ }^{64}$ Finally, medical decision support systems must continue to be designed-current applications in progress relate to pharmacogenomics ${ }^{56}$-so that health professionals can access up-to-the-minute relevant information and respond appropriately to the concerns they hear when interacting with their patients..$^{57}$

With the advancement of genetic technologies and continued workforce shortages of geneticists and genetic counselors, ${ }^{58}$ PCPs will need to assume a greater responsibility in genetics medicine related to the anticipatory guidance and disease prevention that lie within their purview. In the endeavor to improve systems to access genetic providers, alternative options for sharing and maximizing resources should be considered, particularly the use of telehealth and virtual consults. Moreover, streamlining activities among PCPs may result in an overall improvement in access to genetics. As care and management of patients with genetic conditions, as well as the initial evaluation and ordering of genetic tests, becomes integrated into primary care, the specialist's role can be reserved for interpreting genetic test results. As genetic medicine becomes a mainstay of primary care, ensuring an equitable allocation of genetics services is necessary to avoid increased health disparities.

Not surprisingly, there were a number of ELSI barriers identified in the studies reviewed. The two most significant barriers related to the concern for patient anxiety and a fear of health insurance or social discrimination. Additional research regarding the burden and impact of patient anxiety is needed. As for discrimination, in 2008, the Genetic Information Nondiscrimination Act was passed to ensure that a person's genetic information could not be used against him or her in health insurance and employment decisions. Interestingly, 12 of the 14 studies that reported the insurance concerns were published before the enactment of the legislation. However, there remains a gap in awareness of the Genetic Information Nondiscrimination Act, ${ }^{59}$ and in some cases PCPs remain skeptical about the potential of personal genetic information to affect negatively patients' insurability or future coverage. There is a need to educate physicians further about the existence of the Genetic Information Nondiscrimination Act and the protections it offers, as well as the ever-changing legislation regarding genetic medicine.

One of the barriers identified in this study concerned the potential for loss of privacy in the breach of confidentiality for other family members. However, because one of the benefits of genetic medicine is the ability to identify other family members at risk for disease and assist in disease prevention, this barrier should be targeted as part of an effort to deconstruct myths about genetics. Although Acheson et al. ${ }^{37}$ found that $18 \%$ of PCPs surveyed reported social or ethical dilemmas such as the potential to disclose nonpaternity as a barrier, only $1 \%$ reported that their patients refused to disclose the risk of a serious condition to relatives.

This study reinforces findings from previous research that was conducted before the completion of the HGP regarding the hesitations, knowledge gaps, and systems-level challenges in the adoption of genetic medicine into primary-care practice. ${ }^{2}$ The review conducted by Suther and Goodson ${ }^{2}$ assessed PCPs' perceived barriers as well as the quality of 18 studies from an original pool of 68 studies. In addition to identifying similar barriers, Suther and Goodson reported that PCPs cited a need for educational programs in genetics, informational resources, and referral guidelines, which is reflective of our findings as well. This review differs from Suther and Goodson's in that we specifically chose to include only those barriers that were directly reported by PCPs, rather than those based on knowledge models, as a way to evaluate perceptions and attitudes. A major shift in the perceptions regarding genetics medicine in primary care over the past decade is reflected in Supplementary Table S1 online; the majority of studies reviewed concluded that PCPs have positive views of genetics medicine and feel an increasing need to integrate genetic risk assessment and services into routine primary care.

This study's main strength lies in assessing research articles that were primarily designed to assess the available empirical evidence regarding PCPs' perceived barriers to genetic medicine. However, this review contains limitations that should be acknowledged. Barriers in this study were grouped according to the type of barrier as opposed to the theme of the study to which they related, thereby combining barriers that were noted under different contexts (e.g., oncology versus prenatal). However, the assessment of barriers in this manner allows the development of interventions that encompass needs across various settings of genetics in primary care and is not limited to only $\mathrm{FH}$ or genetic testing. Another limitation is that this review contains studies of variable quality, size, and type. Qualitative data contributed to the richness of data, but the comment of one focus group participant holds the same weight as the majority of a national sample reporting another barrier. Also, as with any research, the issues addressed in the published medical literature may be biased toward those of interest to and pursued by the researchers and not the PCPs.

Interventions to address perceived barriers-practical barriers as well as misperceptions and knowledge deficits-must be tailored according to the patient population served and be adapted to the role and identity of the PCP. PCPs who care for patients prenatally, in childhood, and across the life span must understand the implications of genetics medicine for the patients and families they care for as well as their role in providing the services incumbent to them. Advances in genetics, 
genomics, pharmacogenomics, and other "genomic" sciences continue at a rapid rate; to stay abreast of ever-changing guidelines and tests, PCPs must have access to relevant information at the point of care.

Examples of recent efforts to enhance PCP knowledge regarding genetics include the American Academy of Pediatrics Genetics in Primary Care Institute website, ${ }^{60}$ the National Institutes of Health Genetic/Genomic Competency Center, ${ }^{61}$ and the Jackson Laboratory cancer risk assessment tools. ${ }^{62}$ However, development of educational resources alone is unlikely to effect widespread change in attitudes and behavior of PCPs. Existing resources should be promoted and marketing strategies should be aimed at making genetics less intimidating and integrating it into the accepted role of generalists. Payment models must support the integration of new genetic technologies into routine preventive and health supervision models of care. Professional societies should continue to develop specific guidelines, communicate messages to members that dispel existing myths regarding genetics, and provide direction regarding their respective roles in genetic medicine.

PCPs have varying levels of comfort regarding the application of genetics in primary care. Whether they chose to order genetic tests themselves or refer their patients to genetics services, they need to be able to tier patient risk and be prepared to counsel their patients on the implications of test results. Increasingly, PCPs will need to assume a greater responsibility in genetics medicine for the anticipatory guidance and disease prevention that lie within their purview. Addressing the barriers discussed herein is a first step toward realizing this goal.

\section{SUPPLEMENTARY MATERIAL}

Supplementary material is linked to the online version of the paper at http://www.nature.com/gim

\section{ACKNOWLEDGMENTS}

The authors thank the Genetics in Primary Care Institute (GPCI) Project Advisory Committee for its helpful contributions to the manuscript. Support for this research was provided from the Health Resources and Services Administration Maternal and Child Health Bureau (UC7MC21713) for the GPCI, a cooperative agreement awarded to the American Academy of Pediatrics. In addition, B.A.T. was supported by the Clinical Sciences Scholars Program at the University of Michigan and a K23 Mentored Patient-Oriented Research Career Development Award from the National Institute for Child Health and Human Development (K23HD057994).

\section{DISCLOSURE}

The authors declare no conflict of interest.

\section{REFERENCES}

1. Collins FS, McKusick VA. Implications of the Human Genome Project for medical science. JAMA 2001;285:540-544.

2. Suther $S$, Goodson P. Barriers to the provision of genetic services by primary care physicians: a systematic review of the literature. Genet Med 2003;5:70-76.

3. Council, NR. Primary Care: America's Health in a New Era. The National Academies Press, 1996.
4. Hindorff LA, Burke W, Laberge AM, et al. Motivating factors for physician ordering of factor $\mathrm{V}$ Leiden genetic tests. Arch Intern Med 2009;169:68-74.

5. Tong A, Morton R, Howard K, Craig JC. Adolescent experiences following organ transplantation: a systematic review of qualitative studies. J Pediatr 2009;155:542-549.

6. Fuller M, Myers $M$, Webb T, Tabangin M, Prows C. Primary care providers' responses to patient-generated family history. J Genet Couns 2010;19:84-96.

7. Robins R, Metcalfe $\mathrm{S}$. Integrating genetics as practices of primary care. Soc Sci Med 2004;59:223-233.

8. Stermer T, Hodgson S, Kavalier F, Watts S, Jones R. Patients' and professionals' opinions of services for people at an increased risk of colorectal cancer: an exploratory qualitative study. Fam Cancer 2004;3:49-53.

9. Carroll JC, Brown JB, Blaine S, Glendon G, Pugh P, Medved W. Genetic susceptibility to cancer. Family physicians' experience. Can Fam Physician 2003;49:45-52.

10. Huang QR, Trevena L, McIntosh J. GPs' experience and attitudes toward new genetics: barriers and needs. Aust Fam Physician 2004;33:379-380.

11. Bonter K, Desjardins C, Currier N, Pun J, Ashbury FD. Personalised medicine in Canada: a survey of adoption and practice in oncology, cardiology and family medicine. BMJ Open 2011;1:e000110.

12. Bathurst $L$, Huang QR. A qualitative study of GPs' views on modern genetics. Aust Fam Physician 2006;35:462-464.

13. Aalfs CM, Smets EM, de Haes HC, Leschot NJ. Referral for genetic counselling during pregnancy: limited alertness and awareness about genetic risk factors among GPs. Fam Pract 2003;20:135-141.

14. Houwink EJ, van Luijk SJ, Henneman L, van der Vleuten C, Jan Dinant G, Cornel MC. Genetic educational needs and the role of genetics in primary care: a focus group study with multiple perspectives. BMC Fam Pract 2011;12:5

15. Carroll JC, Cappelli M, Miller F, et al. Genetic services for hereditary breast/ ovarian and colorectal cancers - physicians' awareness, use and satisfaction. Community Genet 2008;11:43-51.

16. Al-Habsi H, Lim JN, Chu CE, Hewison J. Factors influencing the referrals in primary care of asymptomatic patients with a family history of cancer. Genet Med 2008;10:751-757.

17. Freedman $A N$, Wideroff $L$, Olson $L$, et al. US physicians' attitudes toward genetic testing for cancer susceptibility. Am J Med Genet A 2003;120A:63-71.

18. Winquist $B$, Ogle $K$, Muhajarine N. Exploring physicians' views and values in relation to maternal serum screening. J Obstet Gynaecol Can 2008;30:564572.

19. Poppelaars FA, Henneman L, Adèr HJ, et al. How should preconceptional cystic fibrosis carrier screening be provided? Opinions of potential providers and the target population. Community Genet 2003;6:157-165.

20. Brandt R, Ali Z, Sabel A, McHugh T, Gilman P. Cancer genetics evaluation: barriers to and improvements for referral. Genet Test 2008;12:9-12.

21. Wood ME, Stockdale A, Flynn BS. Interviews with primary care physicians regarding taking and interpreting the cancer family history. Fam Pract 2008;25:334-340.

22. Iredale R, Jones L, Gray J, Deaville J. 'The edge effect': an exploratory study of some factors affecting referrals to cancer genetic services in rural Wales. Health Place 2005;11:197-204.

23. Sabatino SA, McCarthy EP, Phillips RS, Burns RB. Breast cancer risk assessment and management in primary care: provider attitudes, practices, and barriers. Cancer Detect Prev 2007;31:375-383.

24. Vig HS, Armstrong J, Egleston BL, et al. Cancer genetic risk assessment and referral patterns in primary care. Genet Test Mol Biomarkers 2009;13:735-741.

25. Trinidad SB, Fryer-Edwards K, Crest A, Kyler P, Lloyd-Puryear MA, Burke W. Educational needs in genetic medicine: primary care perspectives. Community Genet 2008;11:160-165.

26. Nagle C, Lewis S, Meiser B, Gunn J, Halliday J, Bell R. Exploring general practitioners' experience of informing women about prenatal screening tests for foetal abnormalities: a qualitative focus group study. BMC Health Serv Res 2008;8:114.

27. Mathers J, Greenfield S, Metcalfe A, Cole T, Flanagan S, Wilson S. Family history in primary care: understanding GPs' resistance to clinical genetics—qualitative study. Br J Gen Pract 2010;60:e221-e230.

28. Williams JL, Collingridge DS, Williams MS. Primary care physicians' experience with family history: an exploratory qualitative study. Genet Med 2011;13:2125

29. Chen MJ, Holt CL, Lose EJ, Robin NH. The use by Alabama pediatricians of genetics consultation in the evaluation of developmental delay. Am J Med Genet A 2008;146A:421-425. 
30. Suther SG, Goodson P. Texas physicians' perceptions of genomic medicine as an innovation. Clin Genet 2004;65:368-377.

31. Lubin IM, McGovern MM, Gibson Z, et al. Clinician perspectives about molecular genetic testing for heritable conditions and development of a clinician-friendly laboratory report. J Mol Diagn 2009;11:162-171.

32. Walter FM, Kinmonth AL, Hyland F, Murrell P, Marteau TM, Todd C. Experiences and expectations of the new genetics in relation to familial risk of breast cancer: a comparison of the views of GPs and practice nurses. Fam Pract 2001;18:491-494.

33. Friedman L, Cooper HP, Webb JA, Weinberg AD, Plon SE. Primary care physicians' attitudes and practices regarding cancer genetics: a comparison of 2001 with 1996 survey results. J Cancer Educ 2003;18:91-94.

34. Poppelaars FA, Adèr HJ, Cornel MC, et al. Attitudes of potential providers towards preconceptional cystic fibrosis carrier screening. J Genet Couns 2004;13:31-44.

35. Rogausch A, Prause D, Schallenberg A, Brockmöller J, Himmel W. Patients' and physicians' perspectives on pharmacogenetic testing. Pharmacogenomics 2006;7:49-59.

36. Welkenhuysen M, Evers-Kiebooms G. General practitioners and predictive genetic testing for late-onset diseases in Flanders: what are their opinions and do they want to be involved? Community Genet 2002;5:128-137.

37. Acheson LS, Stange KC, Zyzanski S. Clinical genetics issues encountered by family physicians. Genet Med 2005;7:501-508.

38. Lowstuter KJ, Sand S, Blazer KR, et al. Influence of genetic discrimination perceptions and knowledge on cancer genetics referral practice among clinicians. Genet Med 2008;10:691-698.

39. Pichert G, Dietrich D, Moosmann P, Zwahlen M, Stahel RA, Sappino AP. Swiss primary care physicians' knowledge, attitudes and perception towards genetic testing for hereditary breast cancer. Fam Cancer 2003;2:153-158.

40. Morgan S, McLeod D, Kidd A, Langford B. Genetic testing in New Zealand: the role of the general practitioner. NZ Med J 2004;117:U1178.

41. Kelly KM, Phillips CM, Jenkins $C$, et al. Physician and staff perceptions of barriers to colorectal cancer screening in Appalachian Kentucky. Cancer Control 2007;14:167-175.

42. Morgan MA, Driscoll DA, Mennuti MT, Schulkin J. Practice patterns of obstetrician-gynecologists regarding preconception and prenatal screening for cystic fibrosis. Genet Med 2004;6:450-455.

43. Bull MJ; Committee on Genetics. Health supervision for children with Down syndrome. Pediatrics 2011;128:393-406.

44. Tinkle BT, Saal HM; Committee on genetics. Health supervision for children with Marfan syndrome. Pediatrics 2013;132:e1059-e1072.

45. Rehder CW, David KL, Hirsch B, Toriello HV, Wilson CM, Kearney HM. American College of Medical Genetics and Genomics: standards and guidelines for documenting suspected consanguinity as an incidental finding of genomic testing. Genet Med 2013;15:150-152.

46. Robson ME, Storm CD, Weitzel J, Wollins DS, Offit K; American Society of Clinical Oncology. American Society of Clinical Oncology policy statement update: genetic and genomic testing for cancer susceptibility. J Clin Oncol 2010;28:893-901.
47. Seaver LH, Irons M; American College of Medical Genetics (ACMG) Professional Practice and Guidelines Committee. ACMG practice guideline: genetic evaluation of short stature. Genet Med 2009;11:465-470.

48. South ST, Lee C, Lamb AN, Higgins AW, Kearney HM; Working Group for the American College of Medical Genetics and Genomics Laboratory Quality Assurance Committee. ACMG Standards and Guidelines for constitutional cytogenomic microarray analysis, including postnatal and prenatal applications: revision 2013. Genet Med 2013;15:901-909.

49. Xierali IM, Hsiao CJ, Puffer JC, et al. The rise of electronic health record adoption among family physicians. Ann Fam Med 2013;11:14-19.

50. Leu MG, O'Connor KG, Marshall R, Price DT, Klein JD. Pediatricians' use of health information technology: a national survey. Pediatrics 2012;130:e1441-e1446.

51. Facio FM, Feero WG, Linn A, Oden N, Manickam K, Biesecker LG. Validation of My Family Health Portrait for six common heritable conditions. Genet Med 2010;12:370-375.

52. Westman J, Hampel H, Bradley T. Efficacy of a touchscreen computer based family cancer history questionnaire and subsequent cancer risk assessment. J Med Genet 2000;37:354-360.

53. Edelman EA, Lin BK, Doksum T, et al. Evaluation of a novel electronic genetic screening and clinical decision support tool in prenatal clinical settings. Matern Child Health J 2014;18:1233-1245.

54. Edelman EA, Lin BK, Doksum T, et al. Implementation of an electronic genomic and family health history tool in primary prenatal care. Am J Med Genet C Semin Med Genet 2014;166C:34-44.

55. Drohan B, Roche CA, Cusack JC Jr, Hughes KS. Hereditary breast and ovarian cancer and other hereditary syndromes: using technology to identify carriers. Ann Surg Oncol 2012;19:1732-1737.

56. Bell GC, Crews KR, Wilkinson MR, et al. Development and use of active clinical decision support for preemptive pharmacogenomics. J Am Med Inform Assoc 2014;21(e1):e93-e99.

57. Korf BR. Genetics and genomics education: the next generation. Genet Med 2011;13:201-202.

58. Korf BR, Feldman G, Wiesner GL. Report of Banbury Summit meeting on training of physicians in medical genetics, October 20-22, 2004. Genet Med 2005;7(6):433-438.

59. Laedtke AL, O'Neill SM, Rubinstein WS, Vogel KJ. Family physicians' awareness and knowledge of the Genetic Information Non-Discrimination Act (GINA). J Genet Couns 2012;21:345-352.

60. American Academy of Pediatrics. Genetics in Primary Care Institute. 2014. http://www.geneticsinprimarycare.org/. Accessed 14 June, 2014.

61. National Institutes of Health, National Human Genome Research Institute. Genetics/Genomics Competency Center for Education. 2014. http://www.g2-c-2.org/. Accessed 14 June, 2014.

62. The Jackson Laboratory. Family History for Cancer Risk Assessment, Testing and Management. 2014. http://www.jaxge.org/. Accessed 14 June, 2014.

63. Korf B. Genetic and genomic competency in medical practice. Virtual Mentor 2012;14:622-626.

64. Nickola TJ, Green JS, Harralson AF, O'Brien TJ. The current and future state of pharmacogenomics medical education in the USA. Pharmacogenomics 2012;13:1419-1425. 